\title{
UNA CULTURA DE CONMEMORACIÓN ES UN CEMENTERIO
}

\section{CULTURE OF COMMEMORATION IS A CEMETERY}

Yamil Leonardi / leonardiyamil@gmail.com Facultad de Artes. Universidad Nacional de la Plata. Argentina

Reseña a Mark Fisher (2019). K-Punk. Volumen 1. Escritos reunidos e inéditos (Libros, películas y televisión). Ciudad Autónoma de Buenos Aires, Argentina: Caja Negra, 392 páginas

Recibido: 23/2/2020

Aceptado: $19 / 5 / 2020$

\section{RESUMEN}

Año 2027: una típica mañana londinense despierta con su bruma gris a los últimos hijos del hombre que se dirigen entonces a la cadena de cafés más cercana antes de empezar su turno en el trabajo. Mientras las bombas estallan afuera y causan apenas un poco de alboroto entre la exacerbada militarización y los intentos de insurrección, alguien lee K-Punk, de Mark Fisher, y sueña con un futuro diferente.

\section{PALABRAS CLAVE}

Cultura popular; ciencia ficción; historia del arte

\begin{abstract}
Year 2027: A typical gray London morning wakes up the last Children of Men who then go to the nearest coffee franchise before starting their shifts. While the bombs detonate outside causing barely a little fuss amongst the exacerbated militarisation and the attempts of insurrection, somebody reads Mark Fisher's K-Punk and dreams of a different future.
\end{abstract}

\section{KEYWORDS}

Popular culture; sci-fi; art history 
«El lenguaje incomparable de la calavera: total inexpresividad

-la oscuridad de las cuencas de sus ojos-

junto a la más salvaje de las expresiones

-la dentadura que sonríe con satisfacción-."

Walter Benjamin [1928] (2018)

"Tenemos que inventar el futuro", decía Mark Fisher en una entrevista realizada el año de otra profecía del fin del mundo. Cinco años después se quitó la vida. No es por romanticismo, sensiblerías o fetichismo por la muerte que hay que iniciar con este dato, sino que se debe más bien a dos motivos: en primer lugar, porque el primer volumen de K-Punk (2019) es el inicio de una colección póstuma de sus textos extremadamente vivos; en segundo lugar, porque dichos escritos son una puja constante entre la vida y la muerte. Las ideas del crítico cultural británico solo vislumbran la potente energía del irrefrenable deseo de inventar el futuro; y, como bien dejaría claro Fisher en múltiples artículos, posts o conferencias, el deseo no teme morir.

No sería errado decir que las formas predilectas de imaginar el futuro, para el autor, siempre fueron las narrativas especulativas, sobretodo la ciencia ficción y el terror. Utopías, distopías, heterotopías: desde James G. Ballard y Margaret Atwood hasta las góticas lecturas de Batman e incluso de Toy Story, pasando por Star Wars, Terminator y Westworld. En la primera parte de lo que será una trilogía, los escritos de Fisher permiten verlo en una de sus facetas oscuras: un historiador especulativo, un trapero del futuro o, lo que es lo mismo decir, un robot historiador en las ruinas, especialmente preocupado por el futuro de las producciones de la cultura pop.

En "Los cafés y los centros de detención", una reseña de la película Children of Men (2006) —que además sirvió como introducción al que tal vez sea su libro más conocido, Realismo capitalista (2016) — Fisher reflota una de las preguntas que el personaje principal, protagonizado por Clive Owen, le hace a un amigo coleccionista de arte. La pregunta resuena como lo que podría ser una pregunta clave de una historia del arte especulativa: ¿Qué te hace seguir? En un mundo apocalíptico a punto de acabarse, un mundo en el que la especie está al borde de la extinción, en el que la humanidad no puede reproducirse, biológica 
ni socialmente, ¿por qué resguardar las producciones culturales del pasado? En un mundo que no produce novedad, ¿quién quedará que pueda disfrutar de lo que se conserva? «Una cultura que tiene lugar solo en los museos ya está exhausta. Una cultura de conmemoración es un cementerio. Ningún objeto cultural puede conservar su poder cuando no hay ojos nuevos para verlo" (Fisher, 2019, p. 267).

Mark Fisher retoma así la oposición entre tradición y reproducción que Walter Benjamin establecería en La obra de arte en la época de su reproductividad técnica [1936] (2007) y añade además una relación de dependencia: sin la reproducción como producción de novedad, incluso la tradición corre el riesgo de perecer. Como fantasmas persistentes en la memoria en degradación de un mundo muerto, nada más queda imaginar uno nuevo (Fisher, 2007). Tarea titánica. K-Punk, de Caja Negra Editora, se encarga de recopilar las críticas imaginativas del autor a fenómenos de agotamiento cultural, así como del rescate de los espectros culturales, en cuanto entidades potencialmente reales; posibles.

El germen de la reseña del film de Alfonso Cuarón se extiende al resto del libro. Línea tras línea de lo que para alguien más parecerían nimiedades se vuelven el objeto de un estudio profundamente potente sobre la cultura actual, desde el rechazo de la idea de una plasticidad total propia de la autoparodia de sagas como Terminator - que plantean la prometeica y meritocrática misión individual de crear un mundo nuevo de la nada-, hasta la celebración de nuevos escenarios, por insignificantes que sean, proyectados hacia el futuro en libros, en películas o en series de televisión.

En la primera parte de K-Punk, como en todos sus escritos, aunque en su modo único, Fisher adopta la postura de un trapero pop. Un coleccionista de los trapos de la cultura popular, que busca obsesionado entre los objetos de tiempos perdidos; objetos en los que, precisamente, radica la posibilidad de desear o imaginar un futuro, porque no hay tiempo más perdido que este. 


\section{REFERENCIAS}

Benjamin, W. [1928] (2018). Calle de una sola mano. Ciudad Autónoma de Buenos Aires, Argentina: Buchwald.

Benjamin, W. [1936] (2007). Conceptos de filosofía de la historia (pp. 147-188). Ciudad Autónoma de Buenos Aires, Argentina: Terramar.

Fisher. M. (13 de enero de 2007). The damage is done [El daño está hecho] [Entrada de blog]. Recuperado de https://k-punk.org/thedamage-is-done/

Fisher, M. (2016). Realismo Capitalista. ¿No hay alternativa? Ciudad Autónoma de Buenos Aires, Argentina: Caja Negra.

Fisher, M. (22 de enero de 2017). "We Have to Invent the Future»: An Unseen Interview with Mark Fisher [Tenemos que inventar el futuro: una entrevista inédita con Mark Fisher]. The Quietus. Recuperado de https://thequietus.com/articles/21616-mark-fisher-interview-capit alist-realism-sam-berkson

Fisher, M. (2019). K-Punk. Volumen 1. Escritos reunidos e inéditos (Libros, películas y televisión). Ciudad Autónoma de Buenos Aires, Argentina: Caja Negra. 